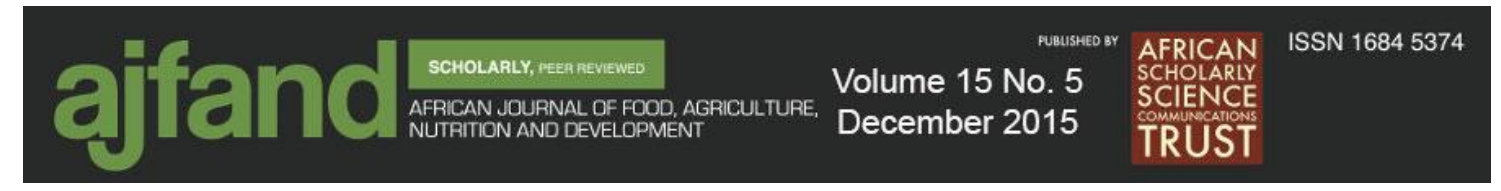

\title{
CENTRAL OBESITY AND DIET QUALITY IN RURAL FARMING WOMEN OF NGAMILAND, BOTSWANA
}

\section{Ramolefhe GT ${ }^{*}$, Nnyepi MS ${ }^{1}$, Ama NO ${ }^{1 \mathrm{a}}$ and Chimbari MJ ${ }^{2}$}

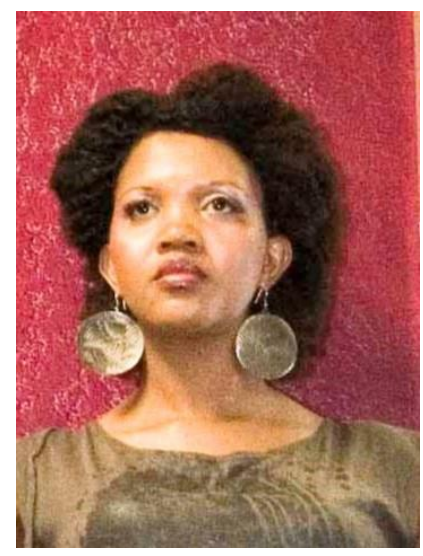

Galase Ramolefhe

*Corresponding author email: gamolph@gmail.com

${ }^{1}$ University of Botswana, Department of Family and Consumer Sciences, P/Bag 00707, Gaborone, Botswana

\footnotetext{
${ }^{1}$ University of Botswana, Department of Statistics, P/Bag 00705, Gaborone, Botswana

${ }^{2}$ University of Kwazulu-Natal, College of Health Sciences, Howard Campus, Durban 4041, South Africa
} 
ABSTRACT

Rapid economic growth in Botswana like in other countries has led to the emergence of nutrition transition. Overweight/obesity, central adiposity and associated co-morbidities are on the rise, especially amongst women. Urban women have been shown to be more prone to overweight/obesity compared to men. However, the situation in rural women has not been studied. Therefore, this paper assesses the prevalence of central obesity in rural female farmers $(\mathrm{N}=113)$ of Ngamiland, Botswana over two years. Estimation of central obesity was made through assessment of waist circumference (WC) and waist hip ratios (WHR). The WHO Indicator cut-off points (WC: low risk $=<80 \mathrm{~cm}$; increased $=80-87.9 \mathrm{~cm}$; and substantially increased $=>88 \mathrm{~cm}$ and WHR: low risk= $\leq 0.85$ and high risk $=0.85+$ ) for risk of metabolic complication were used to categorize women according to body fatness levels. A non-quantified dietary diversity questionnaire was also administered to individuals with responsibility over food, to assess the participant's dietary diversity. Women were assigned dietary diversity scores (DDS) ranging from 0 to 8 , depending on the number of food groups represented in their diet in the past 24 hours. The higher the number the more diversified the diet. These measurements were collected in August 2010 and September 2011. Between 2010 and 2011 the mean WC increased from $87 \pm 11.8$ to $90.2 \pm 14.5$ while the WHRs in 2010 increased from $0.83 \pm 0.1$ to $0.86 \pm 0.1$ respectively. Diets comprised mostly of starchy foods, milk and miscellaneous foods such as fats/oils, sugars, and condiments. Mean DDS for both periods was 3 showing poor quality diet and little change over the two years. Central adiposity was observed amongst the women as shown by a significant increase in $\mathrm{WC}$ between 2010 and $2011(\mathrm{t}=2.818, \mathrm{df}=112, \mathrm{p}=0.006)$. Contrary to expectations that rural female farmers in Ngamiland Botswana would be healthy compared to their non-farming counterparts, there seems to be an observable similar trend of overweight. Furthermore, quality of traditional diets seems to be deteriorating with less consumption of healthy protective and nutrient dense foods, which are likely to influence a rise in metabolic complications. The authors therefore recommend strategies that will facilitate reduction of waist sizes to $80.0 \mathrm{~cm}$ such as farming and consumption of healthier foods such as fruits and vegetables along with the commonly produced ones in the fields. Farming communities should also value and include traditional and wild foods in their diets to increase dietary diversity and reduce the risk of development of chronic diseases.

Key words: Central obesity, Rural Female Farmers, Overweight, Obesity, Ngamiland, Botswana 


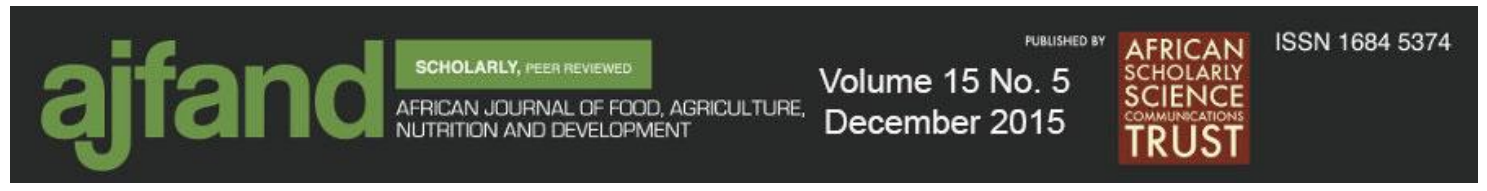

\section{INTRODUCTION}

The greater economic growth in many developing countries has influenced nutrition transition whereby traditional foods and/ or diets are being infiltrated by westernized ones characterized by increased intakes of "refined carbohydrates, added sugars, fats, and animal-source foods" [1]. A sustained pattern of such eating may result in an emergence of health problems such as overweight and obesity which may eventually lead to central adiposity, a risk factor for metabolic complications such as heart problems, cancers, diabetes and hypertension [2]. The prevalence of overweight and obesity and resultant non communicable diseases have become common in African nations and women seem to be affected more than men [3, 4].

Although the literature is consistent about women being prone to overweight/obesity, there is still uncertainty on whether those in rural areas are more affected. Some literature point out that women in urban areas are more overweight/obese than their rural counterparts since urban women are more physically inactive, have increased access to a variety of foods, and consume refined foods high in fat and sugar content [5]. Other studies indicate that women in rural areas, although shown to be less overweight and/or obese than their urban counterparts, seem to have large waistlines which results from overconsumption of energy dense foods and less intake of fiber rich foods $[2,4]$. On the contrary, rural women who depend on agriculture are thought to be thinner than their non-farming counterparts because they are involved in physically intensive farm activities in addition to household chores [6]. Generally farmers are assumed to be healthy because they are thought to consume farm produce that should improve their diets and consequently health. However, it was shown that farmers are exposed to a lot of challenges that may exacerbate health problems such as overweight and obesity [7].

Botswana, now considered an upper middle income country is also undergoing nutrition transition as evidenced by the increasing prevalence of overweight and obesity and emergence of non-communicable diseases [8]. Almost $40 \%$ of the total population is overweight and $33.1 \%$ have high blood pressure with women at higher risk than the rest of the population [8]. Over half (53.4\%) of the women in Botswana are estimated to be overweight and marginal differences exist between urban and rural counterparts $[8,9]$. Nonetheless, there is scanty research in Botswana about the risk of central obesity amongst women in rural farming households; hence the study bridges this gap.

\section{Markers of central obesity}

Central obesity often characterized by bulging of the waist due to fat accumulation in the abdominal area is defined by waist circumference (WC) cutoff over $80 \mathrm{~cm}$ and waist hip ratio (WHR) over 0.85 . These markers were used to estimate central obesity in rural female farmers residing in Ngamiland, Botswana. The two parameters were preferred over body mass index (BMI) derived by dividing body weight in kilograms by height in meters squared, because the latter does not account for the variation in body fat accumulation [10]. Waist circumference is able to strongly measure visceral (surrounding the organs within the peritoneal cavity) abdominal fat mass even in those with normal BMI [11]. Thus it is better at predicting disease risk [10]. Waist 
circumference is directly associated with risks of heart diseases and other chronic diseases and changes in this indicator reflect changes in risk factors of heart and chronic diseases $[10,12]$. Waist-hip-ratio measures abdominal fat accumulation in the waist area in relation to the hip structure. This index can be affected by age dependent factors such as hormones and is a poor predictor in women, hence its use along with WC in this study [13]. Most studies conducted in Botswana have used BMI in the estimation of overweight and obesity $[8,13]$. Few studies in Botswana have used only one body fat indicator (for example, WC or WHR or BMI) but never in combination [8, 14]. Thus this study is one of the few that have used both WC and WHR in estimating abdominal body fat of rural female farmers.

\section{Women and Diet}

A varied diet is essential for optimal health. The more varied the diet is, the higher the likelihood that the diet will provide nutrients supportive of health. In most parts of the world, women have tended to consume inadequate diets that do not promote healthy nutritional status. This is especially true for women in small scale farming, agricultural sector, and/or residing in the rural areas because of the often harsh economic and environmental conditions they endure [6]. The nutrition transition is gradually permeating the non-urban areas as evidenced by a change in dietary patterns. For example, the literature cites that traditional diets characterized by increased fiber, whole grains and wild foods are less consumed [2] with a tendency to intermix these foods with westernized ones $[2,15]$. This dietary pattern is becoming evident in both urban and rural Botswana with the young generation perceiving some of traditional foods as a symbol of primitiveness [16]. This alteration in dietary patterns could also explain why rural women's waistlines are observed to be larger than those of urban counterparts [6]. Even with this evidence that rural women are struggling with health issues amongst which obesity is included, they continue to receive less attention in research. This is masked by the assumption that farming communities especially in rural areas eat healthy diets from their farms, which is supportive of healthy lifestyle than their urban counterparts [17]. Similarly, in Botswana, rural female farmers attract less attention than other population groups, hence the focus on this group in the study. Since literature suggested that women farmers were thinner than their non-farming counterparts coupled with the assumption that their diets were predominantly healthy from farm produce, authors hypothesize that there will be no prevalence of overweight/obesity amongst this study population. The study will provide baseline knowledge on the prevalence of central obesity of rural female farmers in Ngamiland, Botswana in 2010 and 2011, estimated using WC and WHR. Furthermore, there was an assessment of the quality of diet of these rural female farmers during the same period.

\section{METHODS}

This was a repeated cross sectional study design allowing measurements of WC and WHR around the same time in 2010 and 2011 for assessment of change in overweight and obesity prevalence. The study was conducted in Tubu and Shorobe villages and Xobe settlement in the Ngamiland district in the Northern part of Botswana. In Botswana a village is characterized by at least 500 people whereas a settlement has less than this number. Ngamiland district is the third largest district in Botswana housing 
one of the largest inland Delta, the Okavango Delta (OD). All the three study sites are situated along the fringes of this Delta with Tubu on the upper-, Xobe on the mid- and Shorobe on the lower part of the Delta. A selection of women from these areas enabled representation of farmers around the delta and Ngamiland. These sites also provided a range of flooding patterns supportive of different types of molapo farming systems [18, 19]. Communities in Ngamiland especially those around the Delta have abundant natural resources and moist and fertile soils which can be used for flood recession farming also known as molapo farming. However, Ngamiland has registered high poverty levels in its rural areas where almost $50 \%$ are scattered. The major source of their livelihood is agriculture, both livestock and crop production. Ethical clearance to work with the communities was sought from and granted by the University of Botswana, Ministry of Health institution review boards (IRB) and community leadership. The inclusion criteria for participation in the study included being active women farmers, being responsible over household food, residing in Tubu, Shorobe or Xobe, and consenting to having measurements taken. Women who were not active farmers, not responsible over food and not residing in the specified areas were not allowed to participate in this study. Women gave consent before interviews and collection of body measurements. The sample was derived from the available census list of 754, 955 and 375 people in Tubu, Shorobe and Xobe farming households, respectively. From each village list, $10 \%$ of households were randomly chosen giving a total of 209 households ( 75 from Tubu, 96 from Shorobe and 38 from Xobe). From these, heads responsible over households' food were approached and consent was taken to allow participation in the study. Only 161 and 135 farmers were available for interviews and WC and WHR measurements during 2010 and 2011, respectively. Amongst the 161 farmers there were 139 females in 2010 and 115 in 2011 . However, for the current paper, data from 113 women farmers $(\mathrm{N}=113)$ who had all the required data during both periods of 2010 and 2011 were included in the study (Figure 1). Their age range was $18-91$ years.

Central obesity was measured using body fat fatness markers of WC and WHR which were measured in accordance with WHO standards [20]. Categories of WC, namely, low $(<80 \mathrm{~cm})$, increased $(80-87.9 \mathrm{~cm})$ and substantially increased $(>88 \mathrm{~cm})$ risk cut-off points for risk of metabolic complications were used to place individuals according to fat and risk levels [20]. Waist hip ratios were computed by dividing the circumference of the waist in $\mathrm{cm}$ by that of the hip in $\mathrm{cm}$ to derive ratios, $(\leq 0.85$ low risk and $0.85+$ high risk) used to categorize individuals according to body fat levels and were also indicator cut-off points for risk of metabolic complications [20].

A non-quantified dietary diversity questionnaire was administered to women responsible over food in the farming households to measure dietary diversity [21]. With the assistance of this tool, foods consumed by women in the previous 24 hour period were obtained. The questionnaire had been adapted to include traditional and local foods validated in villages similar to study sites. Households were given one score for each food group represented, giving 8 food groups in the tool [22]. Thus the maximum possible dietary diversity score was 8 . The higher the score the more diversified the diet and the higher the nutrient density. This diversity is usually computed using a list of 12 food groups (hence a score range between 0 and 12) representing the number of food 


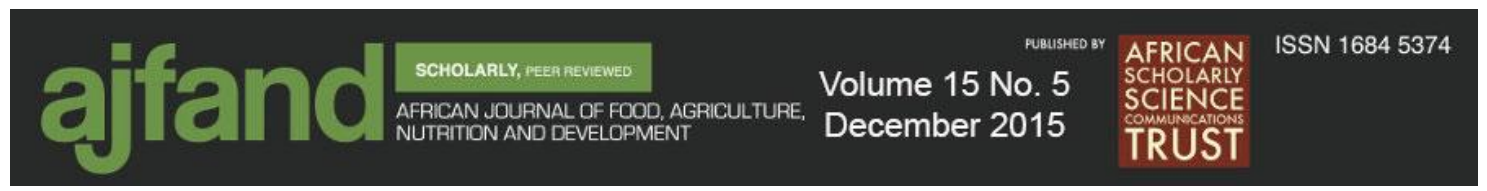

groups. The difference between a tool with a score range of $0-12$ and the one with $0-8$ is that in the latter fats/oils, sugar/honey, spices/condiments and beverages) have been collapsed into one group (others). Eight food groups (cereals, vegetables, fruits, meat, eggs, pulses \& legumes, milk and milk products and others/ miscellaneous) which are major contributors to nutritional quality were chosen to emphasize quality rather than the 12 which indicate socio-economic status and/ or purchasing power [21].

\section{Sampling}

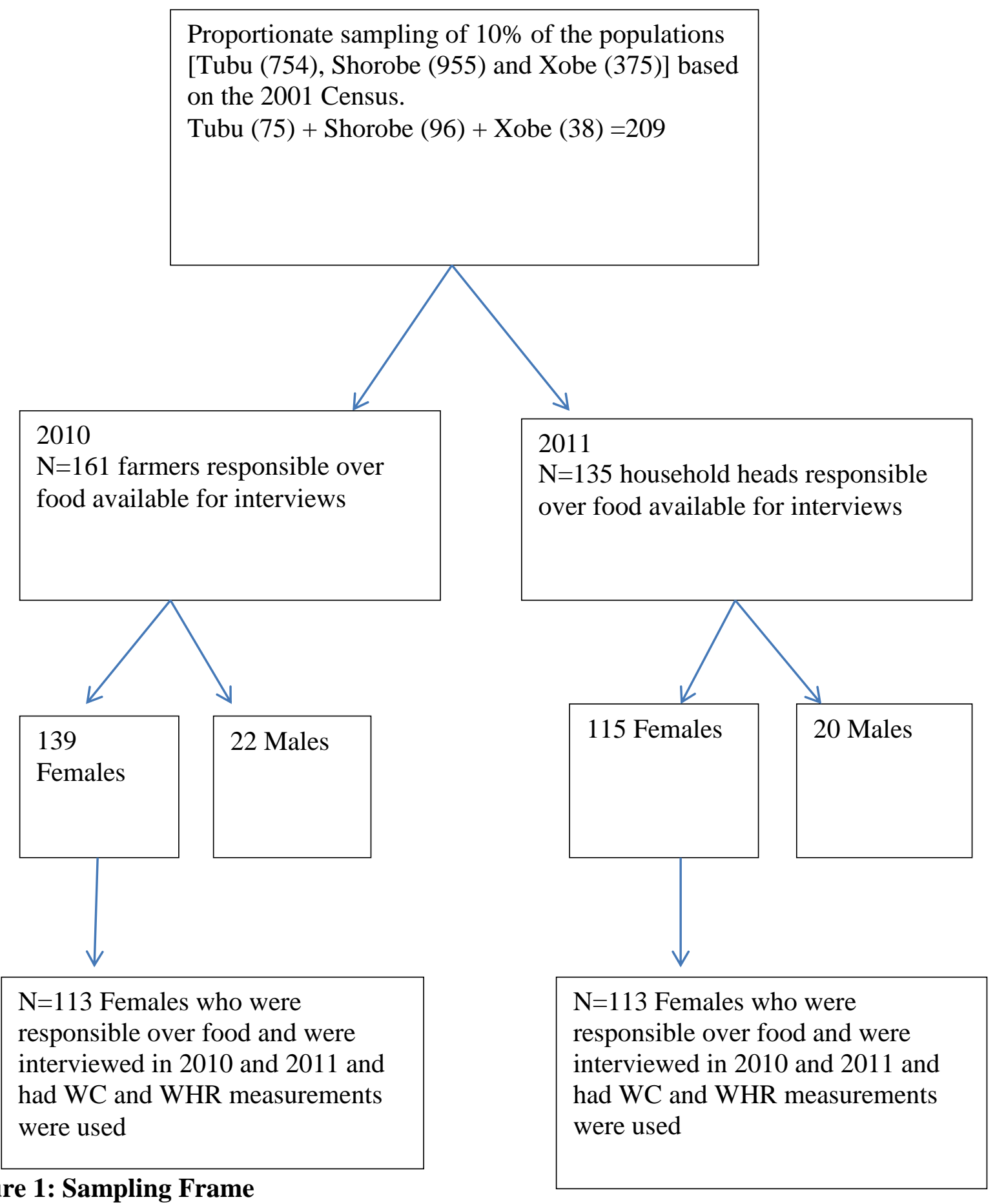

Figure 1: Sampling Frame 


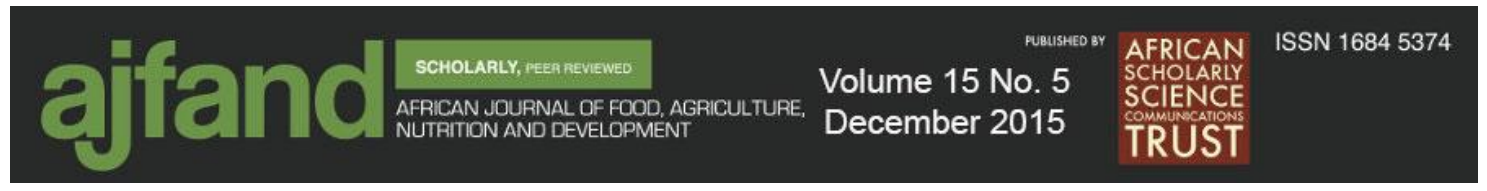

\section{RESULTS}

\section{Central obesity amongst rural female farmers}

\section{Body fat estimation}

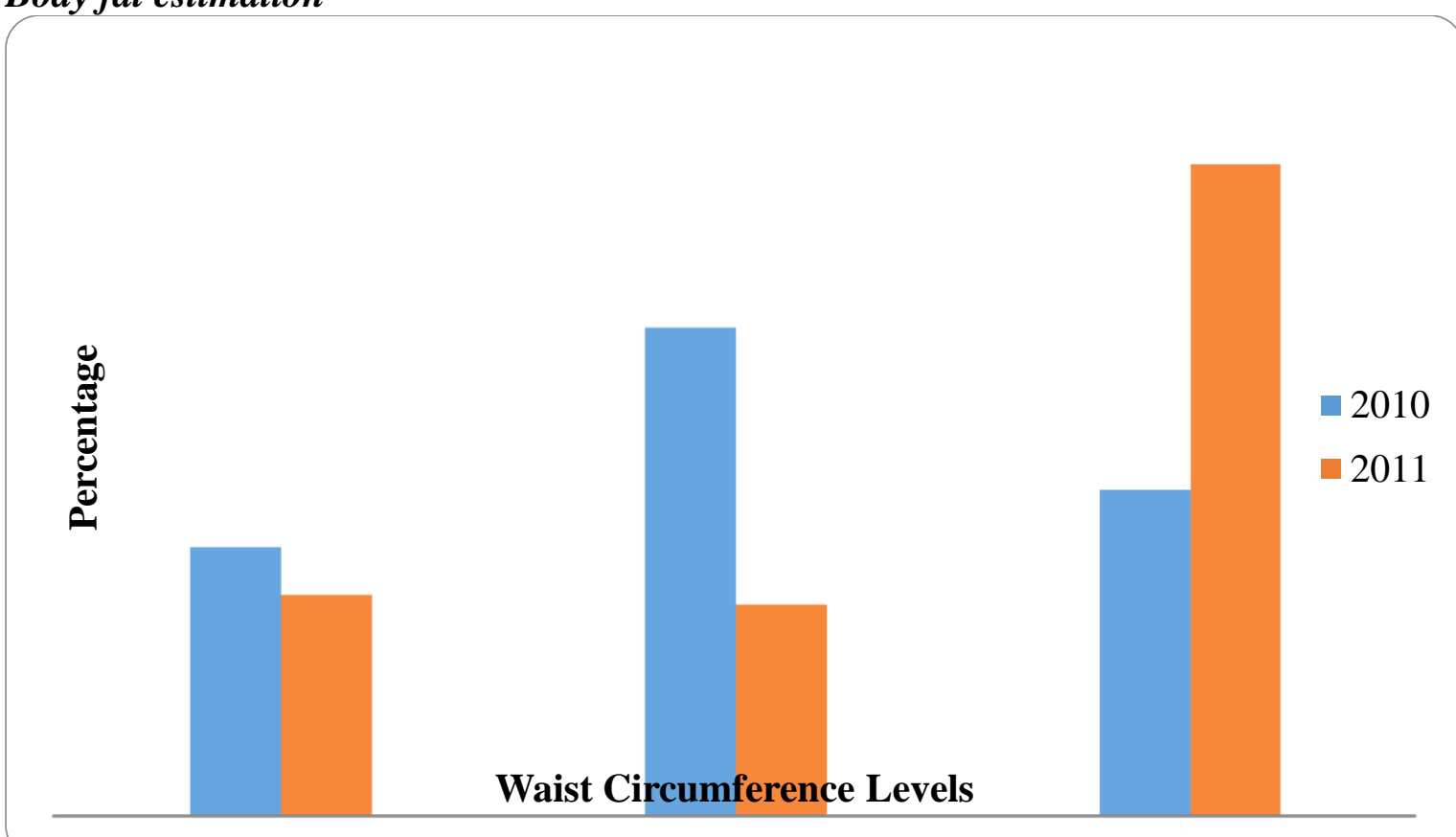

Figure 2: Rural female farmers' waist circumference in 2010 and 2011

The mean \pm SD WC for the rural female farmers was $87.4 \pm 11.8$ in 2010 compared to $90.2 \pm 14.5$ in 2011. Additionally, the mean \pm SD WHR was $0.83 \pm 0.1$ and $0.86 \pm 0.1$ in 2010 and 2011 respectively (Table 1). The proportion of women falling into the low $(<80 \mathrm{~cm})$, increased $(80-87.9 \mathrm{~cm})$, and substantially increased $(>88 \mathrm{~cm})$ risk categories for WC were $24.8 \%, 45.1 \%$ and $30.1 \%$ in 2010 versus $20.4 \%, 19.5 \%$ and $60.2 \%$ in 2010 and 2011, respectively as shown in Figure 2. 

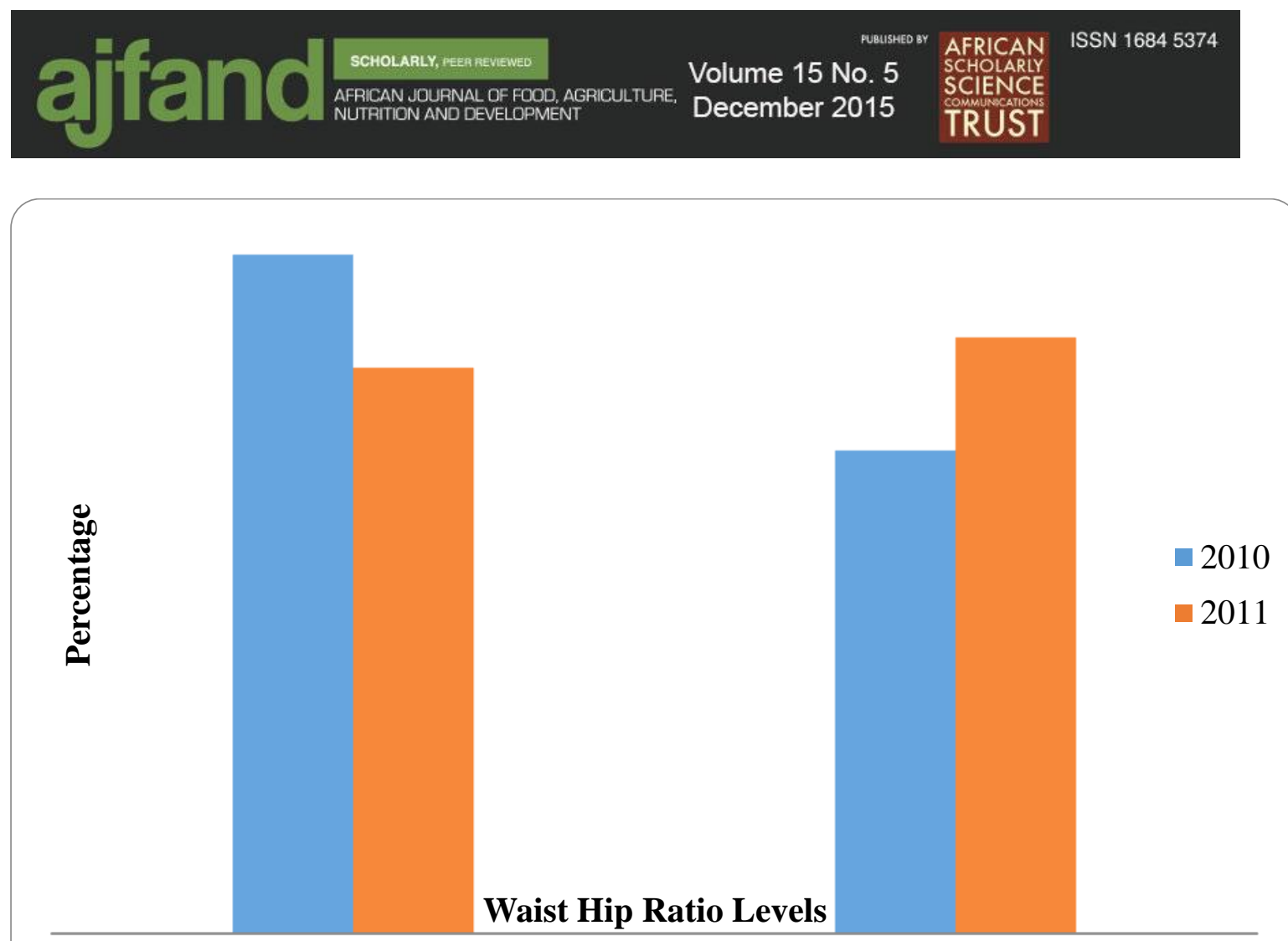

Figure 3: Rural female farmers' waist hip ratio levels in 2010 and 2011

The results revealed that $58.4 \%$ and $41.6 \%$ of female farmers in 2010 versus $48.7 \%$ and $51.3 \%$ in 2011 of the rural female farmers were in the low and high risk categories respectively for WHR (Figure 3). In addition, there was a high and significant correlation between WC in 2011 and $2010(\mathrm{r}=0.695, \mathrm{p}<0.05)$ and a moderate $(\mathrm{r}=$ $0.432, \mathrm{p}<0.05$ ) yet significant WHR correlation in 2011 and 2010 (Table 2).

The Z-test demonstrated that the mean WC in 2011 was significantly greater than that in $2010(\mathrm{Z}=2.818, \mathrm{df}=112, \mathrm{P}$ value $=0.006)$ although there was no significant difference between WHR in 2010 and $2011(\mathrm{Z}=1.929, \mathrm{df}=112, \mathrm{p}=0.056)$ suggesting a stable risk of fatness (Table 3). 


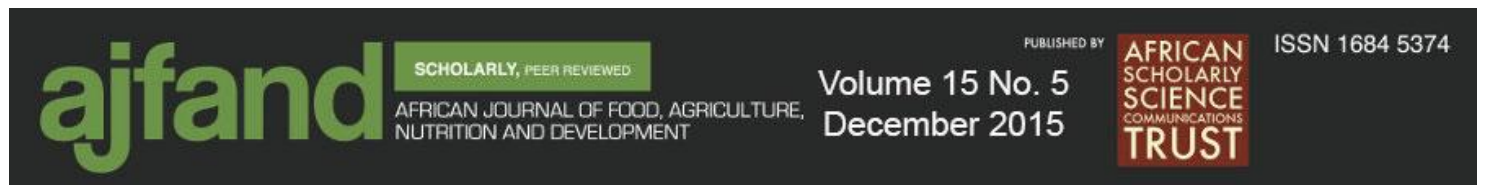

Diet quality of rural female farmers

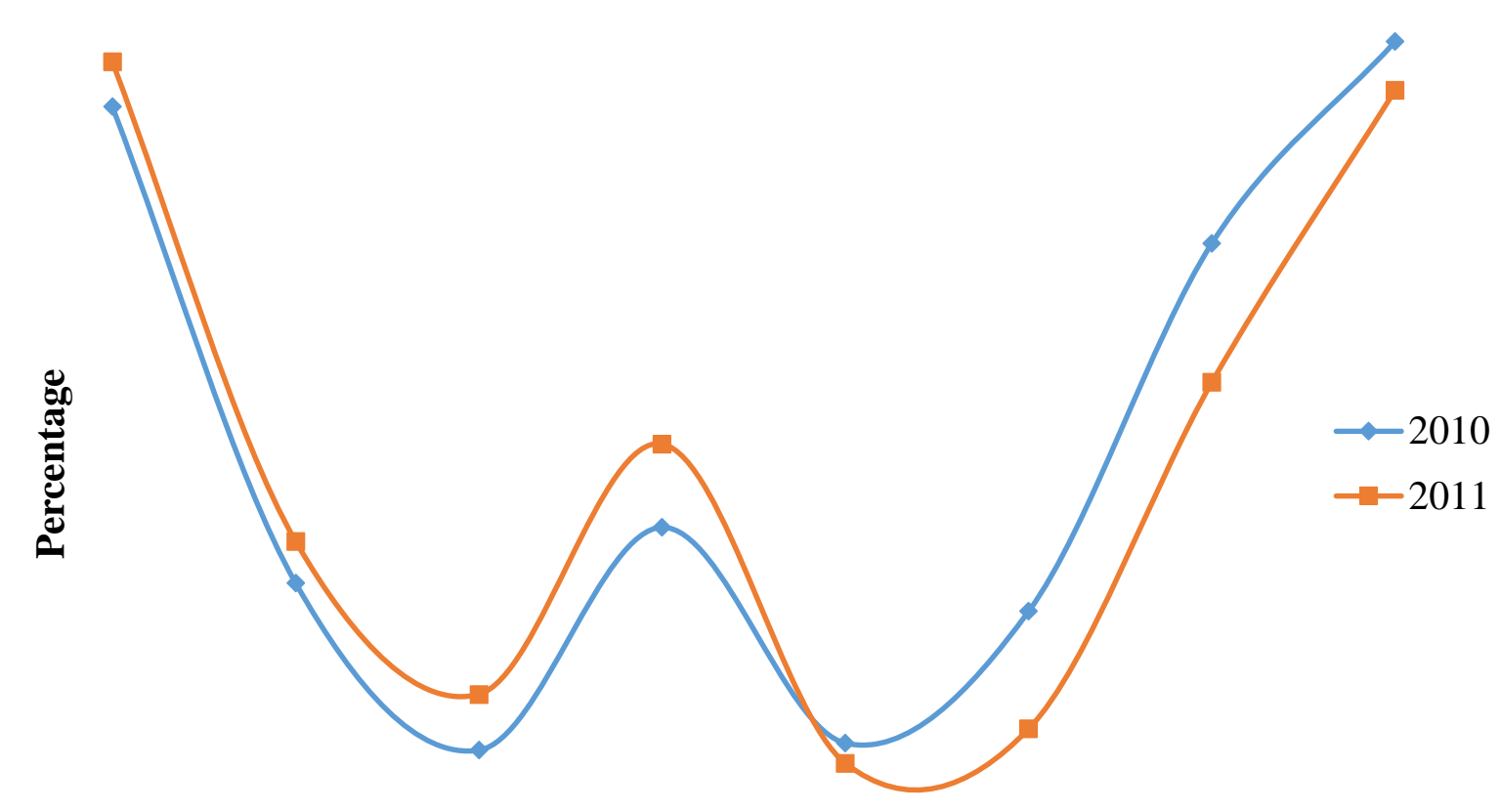

Food Groups

Figure 4: Dietary diversity amongst rural female farmers

Assessment of the frequency with which food groups were represented in household's diets in the previous 24 hours revealed that most (over 85\%) women had meals with food items from the miscellaneous and cereal groups. The next most commonly consumed foods were from the milk and milk products at $68.1 \%$ in 2010 . However, meat and pulses were consumed by less than $50 \%$ of households. Legumes, vegetables, fruits and eggs were the least represented food groups in household's diets in descending order. Similarly, in 2011 , over $87 \%$ of the women maintained consumption of foods from the cereal and miscellaneous food groups. Milk \& products representation in the meals were about the same $(50.4 \%)$ and meat, vegetables, fruits, pulses and legumes and eggs were consumed by less than $43 \%$ of the households (Figure 4).

\section{Dietary diversity scores}

Further assessment of the dietary diversity of the women showed that on average, women had about three food groups represented in their diet in the past 24 hours. The mean \pm SD dietary diversity score was $3.34 \pm 1.18$; with $56.6 \%$ of them consuming diets made up of food items from $\leq 3$ different food groups in 2010. About $43.4 \%$ of the women had their diet made up of food from 4-7 food groups. The most common dietary diversity score for most women was 3 out of a possible of 8 . In 2011, the women had a dietary diversity score of $3.20 \pm 1.10$ mean \pm SD. Furthermore, $61.1 \%$ of these women 


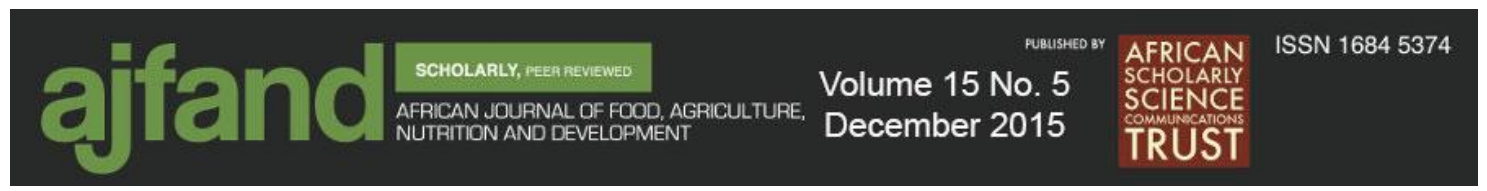

reported eating meals made up of $\leq 3$ different food groups while $38.9 \%$ reported consuming a slightly more diverse diet made of 4-7 food groups. Like in 2010, most women in 2011 had a dietary diversity score of 3 out of a possible of 8 (Table 4). It was further shown that the mean difference of the DDS in 2011 and 2010 were not significantly different from zero, thus implying that both periods had the same mean DDS contrary to speculation under the alternative hypothesis that the dietary composition in 2011 was greater than dietary composition in 2010 (Table 5).

\section{DISCUSSION}

\section{Waist circumference (WC)}

The results showed a statistically significant increase in the WC of rural farming women from 2010 to 2011 indicating an increasing waist size. These results were contrary to our expectations that there would not be increased central adiposity amongst this population. Several factors could be used to explain this outcome. Dietary diversity is one such factor. The results indicated that the female farmers consumed diets largely comprising of carbohydrates, fats and oils and sugar, which were to some extent characteristic of westernized dietary patterns and have tendency to increase waistline [15]. Secondly, unlike typical traditional settings, legumes, fruits (wild and/or commercial) and vegetables were consumed by fewer households. Yet foods from these groups are rich in fiber and are known to be low in energy density. Inclusion of and increase of fiber rich foods in the meals would assist to dilute the energy density of starchy foods thereby supporting a positive change in the waistline. As reported by others, increased consumption of total and cereal fiber had protective effects on weight and waist circumference in European women and men [23]. It has been shown that amidst three dietary patterns (mixed, western and traditional), only the traditional pattern had a protective effect on BMI and WC among women [15]. More women are reported to have an increasing waistline [14]. A study in Botswana showed that more women $(22.5 \%)$ than men $(2.2 \%)$ had abdominal obesity indicated by waist size of over $88 \mathrm{~cm}$ [14]. Although other studies in Botswana used BMI and not WC and/or WHR, they showed that women in Botswana are increasingly becoming bigger. For instance, Batswana women are reported to have a $53.4 \%$ prevalence of overweight when compared with men at $22.1 \%$ [8]. The larger the women become the more complicated their health becomes. The same report by the Ministry of Health showed a pronounced prevalence in chronic diseases such as hypertension and diabetes amongst the female population in Botswana [8]. Observations from other countries such as South Africa agree with results of this study as they show that rural women's waistlines are increasing along with episodes of metabolic complications [24].

\section{Waist hip ratio (WHR)}

Waist hip ratio in the female farmers did not significantly change over the two periods, despite a significant change in the WC index. This probably suggests that WHR has been stable over the two data points, more so that dietary diversity also did not change. Although other studies suggest that compared to WC, WHR had a low sensitivity and specificity [11], the researchers are inclined to believe that women in this study had stable WHR. If they gained any weight over the study period, it was probably proportional. 
There is general paucity of information on the association of WHR and diet in healthy individuals with much research focused on the association of this index and diet in people at risk of chronic diseases. When examining the relationship between WHR and diet in populations at risk of chronic diseases, it was shown that foods that did not quickly raise blood sugar (low glycemic) such as fruits, vegetables and whole cereals were inversely related to WHR although not particularly in women [25]. It has also been shown that even a 1 SD increase in any of the parameters of WC and/or WHR is associated with an increase in morbidity and mortality [26]. Thus the low consumption of vegetables and fruits observed in this study is not desirable and should be addressed.

Despite scientific evidence, which shows rising health complications with increased waistline, some communities view larger body sizes more favorably assuming resemblance of health, beauty, respect and happiness [27]. There are no studies that have reported on the preferred waist size of women in rural areas of Botswana especially farmers. However, studies conducted in other countries show a tendency of women especially those involved in farming and/or those who are hunter-gatherers to have larger waist sizes, which are considered normal and a sign that a woman can better provide for her family even when there are limited resources [28]. A view of large women being normal in some African communities only indicates that education on weight management needs prioritization [9].

\section{Diet quality of rural female farmers}

Women were consuming diets that were energy dense constituting mostly of carbohydrates and fats but low in micronutrient rich foods such as vegetables and fruits. Such diets have been shown to predispose people to increased weight gain, which may lead to poor health. This finding is consistent with other work in Botswana [8]. Consumption of refined carbohydrates, added sugars, fats and increased animal source foods is indicative of deteriorating diet quality of traditional diets. Such a pattern is associated with affluence, hence it is not surprising that much research showed that urban dwellers, who usually have higher income are commonly associated with such diets [29]. Also, since many people in urban areas have replaced traditional diets with western ones, overweight and obesity is more prevalent amongst them [29]. However, recently research showed that there was a marginal difference between urban and rural counterparts. For instance, rural women in Botswana were shown to only be 1.5 times less likely to be overweight/obese [9]. The increasing waistline and consumption of refined and energy dense food amongst rural female farmers challenges this concept and could point to penetration of nutrition transition and urbanization across Botswana, whereby energy dense foods are availed for sale in shops everywhere. As farmers, women in the study depend on sales of farm produce for income which may not be enough to enable supplementation of their diets by buying foods purchased from grocery stores. Faced with this constraint, women may resort to inexpensive low quality foods which though filling may not be nutrient dense. There could also be a challenge of transport to markets and lack of full service supermarkets to buy a variety of fresh produce and nutrient dense foods at fair prices in rural areas. This therefore leaves an option of buying at local convenience stores that sell refined foods with added sugars and fats at much higher prices than in urban centers. These types of foods are likely to 


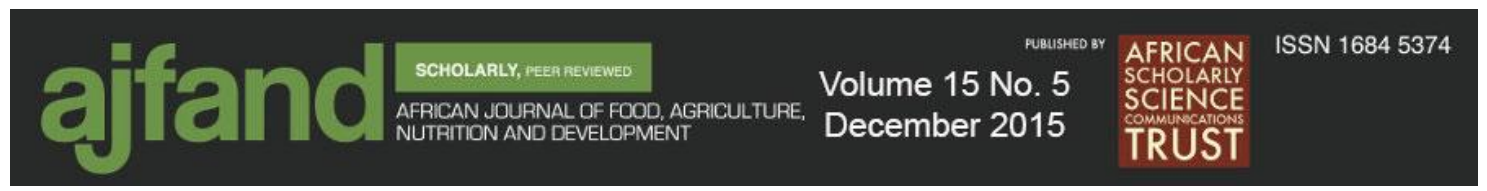

lead to increased calorie intake and weight gain, an important risk factor for development of chronic diseases and needs to be addressed at an early stage.

\section{Dietary Diversity}

The study showed that fewer households in 2010 compared to 2011 consumed meals comprised of food from $\leq 3$ food groups. Furthermore, the number of those consuming meals made of food items from 4-7 food groups was less in 2011 as compared to 2010. Increased DDS is also associated with obesity because of high calorie intake [22]. However, the current study observed a low DDS of 3, which meant that in both years of 2010 and 2011, the dietary diversity of the rural female farmers did not change. Since previous studies showed that increased DDS was associated with obesity and that this was common with people in urban areas, it was not expected that the study population have increasing central adiposity. However, this study found bulging waistlines despite the low DDS. One explanation for this could be increased consumption of carbohydrates, fats and oils. Carbohydrates are a major food group in the diet of Batswana and have been prevailing for generations. However, in the olden days meals were not prepared with added fats and oils because the latter were expensive. In addition, even the cereals were minimally processed, and the diets had relatively high fiber content. Nowadays most people even those from the low income families have good access to fats and oils, hence their frequent use in meal preparation. Oils are also availed to households as part of the food baskets provided to destitutes, orphans, senior citizens, people in home based care programs and the under-fives attending child welfare clinics, hence their use in abundance. To the authors' knowledge, there were no studies that addressed diet quality of female farmers in Botswana. However, some of the work conducted in Botswana addressed diet quality of other populations such as the elderly through use of different systems such as the healthy eating index (HEI), which focused on adequacy, moderation and variety [30]. Overall, the study revealed a poor dietary pattern among the elderly which lacked variety and indicated an inadequate intake of micronutrient rich foods such as vegetables and fruits. This pattern was also evident in the present study. Further, the increased consumption of fats and oils and simple sugars which is characteristic of alteration in traditional diets and to some extent nutrition transition were reported by most households. However, the authors acknowledge some limitations that warrant cautious interpretation of the results. For instance, data was collected twice over the two period spans and thus does not guarantee sufficient time to conclude that the female farmers' diets showed nutrition transition and or replacement with western diets. Moreover, the study sample was small and the researchers recommend the conduction of a similar study with a larger sample size for the results to be generalized to a wider population of rural women farmers. Nonetheless, the study had strengths. For example, this was the first study in Botswana to direct its attention towards women farmers. Moreover, it used two strong markers of obesity, WC and WHR, which are able to account for variation in abdominal fat mass even amidst a normal BMI. Results from this study will sensitize the nation and health community on the health status of women farmers, which is important in giving direction on target areas to help in the improvement of their health. 


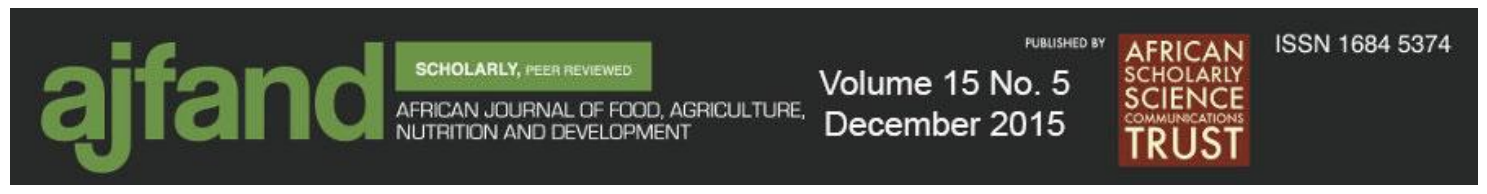

\section{CONCLUSION}

Contrary to expectations that rural female farmers in Ngamiland Botswana would be healthier compared to observations in urban women, there seemed to be an observable increasing trend of central obesity. Furthermore, quality of traditional diets seemed to be deteriorating which may increase the rise of metabolic complications. The authors recommend strategies that will facilitate reduction of waist size to $80.0 \mathrm{~cm}$ for women in order to reduce the risk of metabolic complications. These strategies could include promotion of farming and consumption of healthier foods such as fruits and vegetables along with the commonly produced ones in the fields and integrating nutrition education especially about weight management for health benefits into programs for farmers. Farming communities should also be encouraged to value and include traditional and wild foods in their diets for diversity. A combination of these interventions can help rural farming communities and everyone in general to adopt healthier lifestyles and curb the risk of diseases associated with central obesity.

\section{ACKNOWLEDGEMENTS}

The research was funded by Botswana Ecohealth Project (BEP) through The International Development Research Centre (IDRC) in Canada. 


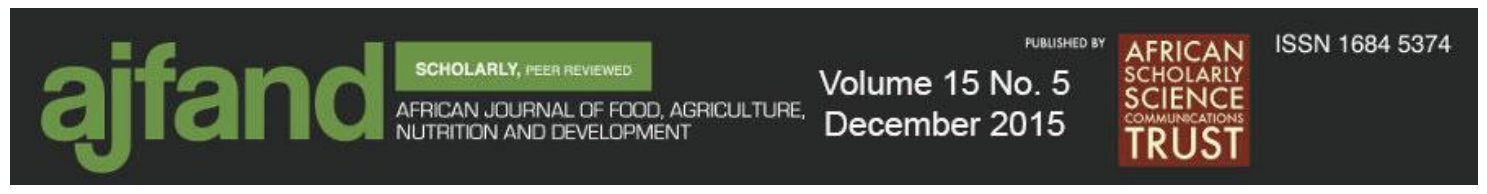

Table 1: Waist circumference and waist hip ratio descriptive for different periods

\begin{tabular}{|c|c|c|}
\hline \multirow[t]{3}{*}{ Year } & Mean waist circumference \pm & Mean waist hip ratio \pm \\
\hline & SD & SD \\
\hline & \multicolumn{2}{|l|}{$\mathrm{N}=113$} \\
\hline 2010 & $87.4 \pm 11.8$ & $0.83 \pm 0.1$ \\
\hline 2011 & $90.2 \pm 14.5$ & $0.86 \pm 0.1$ \\
\hline
\end{tabular}

Table 2: Paired Sample Correlations for WC \& WHR

\begin{tabular}{lccl}
\hline Pair & N & Correlation & p-value \\
\hline 1: WC in 2011 \& WC in 2010 & 113 & 0.695 & $<0.001$ \\
& & & \\
2: WHR in 2011 \& WHR in 2010 & 113 & 0.432 & $<0.001$ \\
\hline
\end{tabular}

Waist circumference (WC), Waist hip ratio (WHR), Sample size (N) 


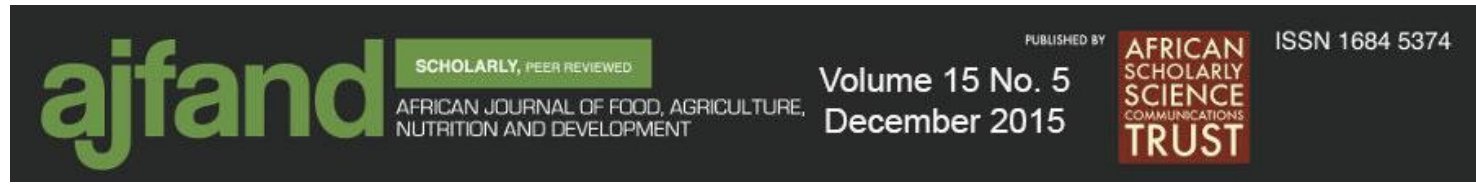

Table 3: Z-test for WC \& WHR

\begin{tabular}{llll}
\hline Pair & Mean & Z & p-value \\
\hline 1: WC in 2011 \& WC in 2010 & 2.81 & 2.818 & 0.006 \\
2: WHR in 2011 \& WHR in 2010 & 0.16 & 1.929 & 0.056
\end{tabular}

Waist circumference (WC), Waist hip ratio (WHR), Z statistic (Z)

Table 4: Dietary diversity scores of women according to periods

\begin{tabular}{ccc}
\hline Year & Dietary diversity scores & $\begin{array}{c}\text { Frequency of women \& } \\
\text { dietary diversity }\end{array}$ \\
& & N $(\%)$ \\
\hline 2010 & $3.34 \pm 1.18$ & $56.6 \%-----\leq 3$ Food groups \\
& Mode=3 & $43.4 \%----4-7$ Food groups \\
& $3.20 \pm 1.10$ & $61.1 \%----\leq 3$ Food groups \\
& Mode=3 & $38.9 \%----4-7$ Food groups \\
\hline
\end{tabular}




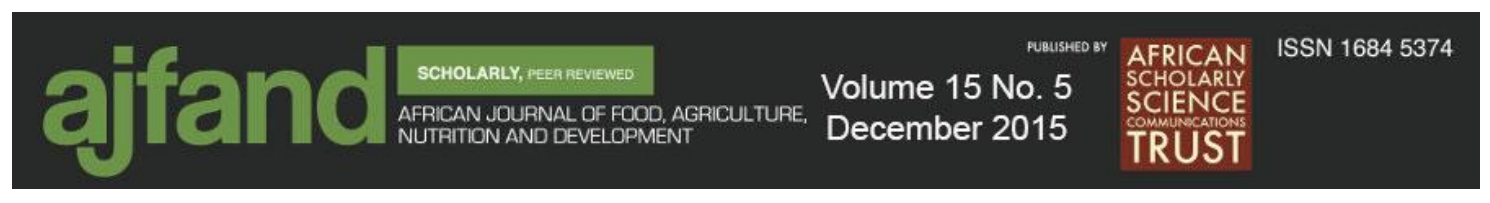

Table 5: Z-test for Dietary Diversity Scores

\begin{tabular}{llll}
\hline Pair & Mean & Z & p-value \\
\hline 1: DDS in 2011 \& DDS in 2010 & 0.13 & 0.946 & 0.346 \\
\hline
\end{tabular}

Dietary diversity score (DDS), Z statistic (Z) 


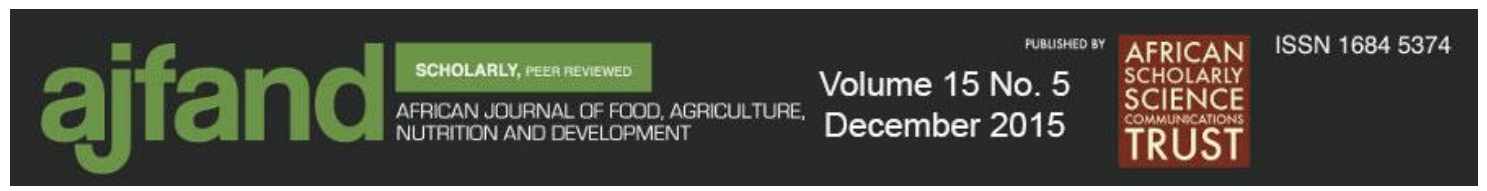

\section{REFERENCES}

1. Keding GB, Msuya JM, Maass BL and MB Krawinkel Dietary patterns and nutritional health of women: the nutrition transition in rural Tanzania. Food and Nutr Bulletin 2011; 32(3):218-226.

2. Steyn NP, Nel JH, Parker W, Ayah R and D Mbithe Dietary, social, and environmental determinants of obesity in Kenyan women. Scand J Public Health 2011; 39: 88-97.

3. Ono T, Guthold R and K Strong WHO global comparable estimates, 2005. Available at: http://infobase.who.int/infobase. Accessed on 13/08/2013.

4. Goedecke JH, Jennings CL and E Lambert Obesity in South Africa. Chronic Diseases of Lifestyle in South Africa since 1995-2005. 2005; 7: 65-79.

5. Akarolo-Anthony SN, Odubore FO, Yilme S, Aragbada O, Odonye G, Hu F, Willett W, Spiegelman $D$ and CA Adebamowo Pattern of dietary carbohydrate intake among urbanized adult Nigerians. Int J Food Sci Nutr 2013; 64(3):292-9.

6. Barker M, Chorghade G, Crozier S, Leary S and C Fall Socio-economic factors, lifestyle and gender differences in body mass index in rural India. $J$ Nutr 2006; 136:3062-3068.

7. Brumby SA, Willder SJ and J Martin The sustainable farm families' project: changing attitudes to health. Rural Remote Health 2009; 9(1):1012.

8. Ministry of Health. Republic of Botswana Chronic Disease Risk Factor Surveillance Report. Botswana Steps Survey, Gaborone, 2007.

9. Letamo $\mathbf{G}$ The prevalence of and factors associated with overweight and obesity in Botswana. J. Biosoc. Sci. 2011; 43:75-84.

10. Ejike $\mathbf{C}$ and I Ijeh Obesity in young-adult Nigerians: Variation in prevalence determined by anthropometry and bioelectrical impedance analysis, and development of \% body fat prediction equations. Int Arc Med 2012; 5(22):1-7.

11. Odenigbo UM, Odenigbo UC, Oguejiofor OC and POU Adogu Relationship of waist circumference, waist hip ratio and body mass index as predictors of obesity in adult Nigerians. Pakistan J Nutr 2011; 10(1):15-18.

12. Gharakhanlou R, Farzad B, Agha-Alinejad H, Steffen LM and M Bayati Anthropometric measures as predictors of cardiovascular diseases risk factors in the urban population of Iran. Arq Bras Cardiol 2012; 98(2):126-135.

13. Canoy D Distribution of body fat and risk of coronary heart disease in men and women. Curr Opin Cardiol 2008; 23:591-8. 


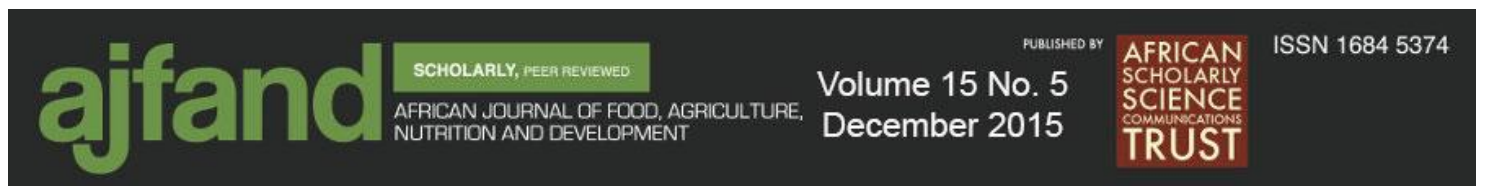

14. Kwape LD, Sarwar N, Masson LF and G McNeill Diet and CVD risk factors in Botswana. P Nutr Soc 2011; 70: E193.

15. Cunha DB, Rodrigues de Almeida RMV, Sichieri $R$ and RA Pereira Association of dietary patterns with BMI and waist circumference in a lowincome neighbourhood in Brazil. Brit J Nutr 2010; 104:908-913.

16. Shaibu S, Holsten JE, Stettler N, Maruapula SD, Jackson JC, Malete L, Mokone G, Wrotniak BH and CW Compher Adolescent Obesity Prevention in Botswana: Beliefs and Recommendations of school Personnel. J Sch Nurs 2012; 28: 220-229.

17. Brumby $\mathbf{S}$, Chandrasekara A, McCoombe $\mathbf{S}$, Kremer $\mathbf{P}$ and $\mathbf{P}$ Lewandowski Farming fit? Dispelling the Australian Agrarian myth. BMC Research Notes 2011; 4:89.

18. John N, Teketay D, Masamba W and $\mathbf{K}$ Kashe Diversity, population structure and regeneration status of woody species in dry woodlands adjacent to molapo farms in Northern Botswana. J For 2013; 3(4):138-151.

19. Chirebvu E, Chimbari MJ and BN Ngwenya Assessment of risk factors associated with malaria transmission in Tubu village, Northern Botswana. Mal Res \& Treat. 2014:1-9.

20. World Health Organization (WHO) Waist Circumference and Waist-Hip Ratio: Report of a WHO Expert Consultation, Geneva, 8-11, 2008.

21. Swindale A and P Bilinsky Household Dietary Diversity Score for Measurement of Food Access: Indicator Guide (version 2). Food and Nutrition Technical Assistance Project, Academy for Education Development, Washington DC, 2006.

22. Jayawardena, R, Byrne NM, Soares MJ, Katulanda P, Yadav B and AP Hills High dietary diversity is associated with obesity in Sri Lankan adults: an evaluation of three dietary scores. BMC Public Health 2013; 13:314-321.

23. Du H, van der A DL, Boshuizen HC, Forouhi NG, Wareham NJ, Halkjoer Jytte J, Tjønneland A, Overvad K, Uhre Jakobsen M, Boeing H, Buijsse B, Masala G, Palli D, Sørensen TIA, Wim HM Saris WHM and EJM Feskens Dietary fiber and subsequent changes in body weight and waist circumference in European men and women. Am J Clin Nutr 2010; 91:329-36.

24. Motala A, Pirie FJ and MAK Omar The prevalence of metabolic syndrome and determination of the optimal waist circumference cutoff points in a rural South African community. Diab Care 2011; 34:1032-1037. 


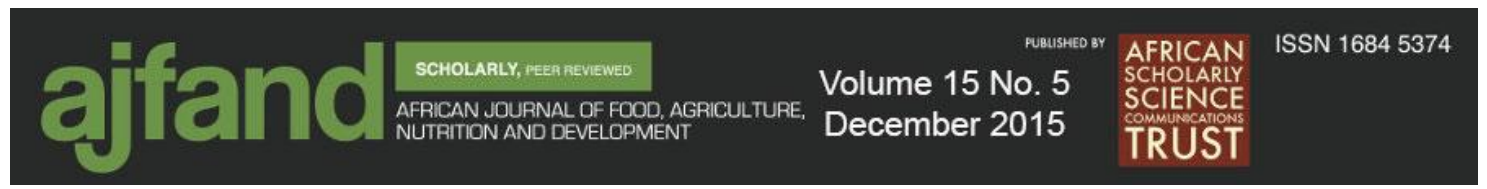

25. Mosdol A, Witte DR, Frost G, Marmot MG and EJ Brunner Dietary glycemic index and glycemic load are associated with high-density-lipoprotein cholesterol at baseline but not with increased risk of diabetes in the Whitehall II study. Am J Clin Nutr 2007; 86:988-994.

26. Coutinho T, Goel K, Correa de Sa D, Kragelund C, Kanaya AM, Zeller M, Park J, Kober L, Torp-Pdersen C, Cottin Y, Lorgis L, Lee S, Kim Y, Thomas R, Rooger VL, Somers V and F Lopez-Jimenez Central obesity and survival in subjects with coronary artery disease: A systematic review of the literature and collaborative analysis with individual subject data. J. Am Coll of Cardiol. 2011; 57(19):1877-1886.

27. Mchiza ZJ, Goedecke JH and EV Lambert Intra-familial and ethnic effects on attitudinal and perceptual body image: a cohort of South African motherdaughter dyads. Bio Med Centr Public Health. 2011; 11:433.

28. Cashdan E Waist-to hip ratio across cultures: Trade-offs between androgen and estrogen dependent traits. The Wenner-Gren Foundation for Anthropological Research, 2008.

29. Singh D, Dixon BJ, Jessop TS, Morgan B and AF Dixson Cultural consensus for waist-hip ratio and women's attractiveness. Evol Hum Behav 2010; 31: 176181.

30. Maruapula SD and KM Chapman-Novakofski Poor Intake of Milk, Vegetables, and Fruit with Limited Dietary Variety by Botswana's Elderly. $J$ Nutr Elderly 2008; 25(3-4):61-72. 